\title{
DEVELOPMENT OF CUTTING FLUID FROM SPENT ENGINE OIL
}

\author{
C. P. Nwadinobi ${ }^{1}{ }^{*}$ and J. U. Okoli ${ }^{2}$

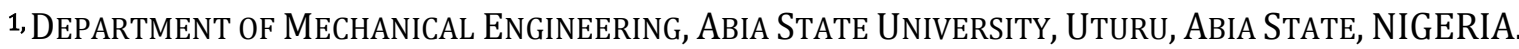

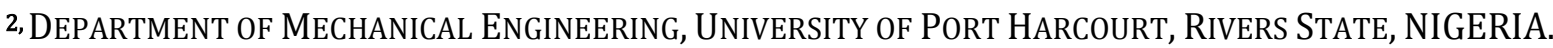 \\ E-mail addresses: ${ }^{1}$ chibundop@gmail.com, 2 freeumunnahappy@yahoo.com
}

\begin{abstract}
The suitability of cutting fluids formulated from spent engine oil has been considered. In the formulation, recycled Spent Engine Oil was used as a base oil, liquid washing soap as emulsifier, phenol was applied as disinfectant while sulphur served as extreme pressure agent. Analysis and comparative assessment of the physical-chemical properties of samples of cutting fluid was conducted. From the performance analysis, the optimal sample has values such as flash point, $205.92^{\circ} \mathrm{C}$; pour point, $-13.04^{\circ} \mathrm{C}$. Viscosity, at $40^{\circ} \mathrm{C}$ gave an average value of $96.06 \mathrm{cst}$. At $100{ }^{\circ} \mathrm{C}$, have average value of 7.57 cst. The sample has average $p H$ value of 9.03. In corrosion grading, it rated non-corrosive. Furthermore, the effectiveness of the developed products was measured, among other parameters, through tool tip temperature, material removal rate and tool tip wear. Sample VII presented the least mean temperature of $32.5^{\circ} \mathrm{C}$. Sample III presented the minimum mean value of tool tip wear. Sample VII gave the best material removal rate of $5.68 \mathrm{~g} / \mathrm{min}$. From the results obtained from the analysis, the developed spent engine oil based cutting fluid samples compared favourably with the conventional cutting oil, thus making them acceptable for machining application and can also be an economical choice for use in machining processes.
\end{abstract}

Keywords: Spent engine oil, Cutting Fluid, Turning, Regeneration process, Comparative assessment.

\section{INTRODUCTION}

Access to lubricants is essential to any modern society and not only does lubrication reduce friction and wear by interposition of a thin liquid film between moving surfaces of various machinery/equipment or during machining operations, it also removes heat, keeps equipment clean, and prevents corrosion. It also minimizes material wear, improves the efficiency of equipment /machinery and acts as fuel. A lubricating oil becomes unfit for further use for the two main reasons of accumulation of contaminants in the oil and chemical changes in the oil. Thus, spent/waste lubricating oil refers to the engine oil, transmission oil, hydraulic and cutting oils unfit for use. These contaminants include metals, ash, carbon residue, water, varnish, gums, and other contaminating materials, in addition to asphaltic compounds which result from the bearing surface of the engines [1 - 4]. Spent engine oil is a high pollutant material as they pose significant impact on both the economy and environment, therefore it requires responsible management. This material may cause damage to the environment when dumped/discharged into the ground or into water streams or even burnt as a low grade fuel, which may result in groundwater, soil and atmospheric contamination [5].

This used oil needs proper management to make it a valuable product by minimizing the quantity of oil being improperly disposed-off and reducing the waste oils environmental burden. Therefore a recommended solution for this issue is the recovery of the lubricating base oil from the waste oil. Recycling/regeneration of such contaminated materials using safe and cost effective materials/methods will be beneficial in reducing engine oil costs, have a significant positive impact on the environment [6 - 8]. Once the spent engine oil has been collected, treated and analyzed based on its physical-chemical parameter, it has assumed different classification as it can now be used for different purposes including serving as base stock for engine oil as well as being utilized for metal cutting fluid formulation.

The cutting fluid functions are primarily: cooling of the cutting tool, workpiece and chips; reduction of friction at the contact surface; and reducing or preventing adhesion of the cutting tool and workpiece or chips at 
the contact surface. Also, flushing away of chips from the cutting zone and protecting the workpiece and tool from corrosion [9 - 12]. Even with the importance of cutting fluid in machining, investigations have shown that this commodity usually heightens the cost of machining [13 - 15]. Despite this issue raised, dry and near-dry machining will not in the near future, replace wet machining because of its low efficiency in large scale machining [16].

It is therefore imperative that the use of cutting fluids is rather inevitable in general machining operations. This underscores the need for the development of alternative cutting fluid which can take care of the cost effectiveness observed in machining operations due to cost of cutting fluid. Hence, this study is being undertaken on the formulation and performance analysis of cutting fluid using spent engine oil based cutting fluid as an alternative to the conventional cutting fluids in use in the machining industry. The properties of the spent engine oil will be improved so as to meet the requirement of serving as a cutting fluid. In addition, a comparative evaluation of the properties of conventional cutting fluid and that of spent engine oil based cutting fluid will be undertaken. This is in addition to ascertaining the effectiveness through comparison of the developed cutting fluid, dry cutting and a commercial cutting fluid with respect to the performance parameters of Tool Tip Temperature, Material Removal Rate (MRR) and Tip Wear during turning of mild steel bar. Therefore, this study is aimed at contributing to solving the environmental challenge posed by poor disposal of waste lubricants in developing countries. This is by converting it to useful alternative for the cutting fluid formulations and application. In addition, it will also amount to a waste to wealth programme.

\section{METHODOLOGY}

The basic principle of processing spent engine oil as cutting fluid follows these basic steps: Removal of water and solid particles by settling; Acidic treatment to remove gums, greases, etc; Alkaline treatment to neutralize acid; Adsorbent (Clay, Activated Charcoal,
Fuller's Earth, etc) contacting to bleach the oil and absorb impurities; Filtering to remove adsorbent and other solids; Blending to specification with the introduction of relevant additives $[1,4,17,18]$.

The used engine oil was collected from a motor car mechanic garage in Choba. Bleaching earth (Kaolin) from Ohia in Abia State was used. The apparatus used were: Aluminum pan, burner, distilled water, jars, sieve, conical flask, bowls, electric oven, filter medium, mortar and pestle, weighing balance. This experiment and the follow up analysis of the physical-chemical properties of the obtained cutting fluid samples were carried out at the Central Service Laboratory of National Root Crop Research Institute, Umudike in Abia State of Nigeria.

The clay preparation and activation procedure utilized in this work was as prescribed by $[19,20]$. The spent engine oil was taken through purification process using activated clay. Activated clay of $30 \mathrm{~g}$ mass was mixed with 300g of the spent engine oil that has been already heated to a temperature of $90^{\circ} \mathrm{C}$. The mixture was stirred together thoroughly with the aid of a stirrer for 20 minutes. The mixture was kept till the next day so that there will be some chemical reaction between the spent oil and the activated clay. The impurities in the spent engine oil, had already settled at the bottom of the container by the next day with the clay particles then the oil was sieved with the aid of a filter medium. The oil sample obtained from the purification process was used in preparing the cutting fluid using the blending description given by [21,22]. Eight samples of cutting fluids were prepared, with varied percentage volume composition of the constituent materials as shown in Table 1. Experiments were also conducted to determine some important physical-chemical properties of cutting fluid using the produced samples from spent engine oil based cutting fluids. These properties are: Flash Point, Pour Point, Viscosity value, Corrosion value and $\mathrm{pH}$ value. In order to achieve this, 180 samples were analyzed; these samples include the 8 processed samples with the unprocessed spent engine oil sample. For each of these samples, 20 batches of experiment were conducted.

Table 1: Summary of Cutting Fluid samples formulation

\begin{tabular}{|c|c|c|c|c|c|c|c|c|c|}
\hline \multirow{2}{*}{ Material } & \multirow{2}{*}{ Function } & \multicolumn{8}{|c|}{ Sample Content (\% volume) } \\
\hline & & I & II & III & IV & $\mathrm{V}$ & VI & VII & VIII \\
\hline Recycled Spent Engine Oil & Base Oil & 90 & 85 & 80 & 80 & 75 & 65 & 60 & 55 \\
\hline Liquid Washing Soap & Emulsifier & - & - & - & 10 & 14 & 22 & 25 & 28 \\
\hline Phenol & Disinfectant & 5 & 5 & 5 & 5 & 5 & 5 & 5 & 5 \\
\hline Sulphur & Extreme Pressure agent & 5 & 10 & 15 & 5 & 6 & 8 & 10 & 12 \\
\hline
\end{tabular}


ASTM D92 method was used in the test for Flash Point of the sample of oil. Under this test, $10 \mathrm{ml}$ of the produced sample of oil was introduced into a $100 \mathrm{ml}$ beaker and then a thermometer is inserted vertically into the sample oil and held vertical with the thermometer holder (retort stand) such that the bottom of the bulb is slightly above base of the beaker. The bubbles present on the surface on the sample oil during heating are removed off with the aid of stirrer. The beaker was placed on a Heater (Binatone electric stove) or Water Bath (GFL, Type-1083, No-11279395J). After a while, the sample is observed to smoke vigorously. From that smoke point, a flame source was brought at intervals to determine the temperature at which a flash appears on the surface of the sample while the oil in the beaker was heated. The test flame applicator was lowered to the center of the beaker with smooth continuous motion. The time spent in passing the test flame across the beaker in each case was per $1^{\circ} \mathrm{C}$ successive thermometer reading. When a flash appeared on the surface of the oil, the temperature at that point is noted as the flash point (The flash point is the lowest temperature at which application of the test flame causes the vapor above the sample to ignite). The test is then repeated.

The ASTM D97 method was used in the Pour Point test of the sample of oil. Processed oil sample of $20 \mathrm{ml}$ quantity was introduced into a boiling flask and first heated to $45^{\circ} \mathrm{C}$ in a water bath, and maintained for few minutes. The oil sample was ice-cooled. The flask was tilted to check the movement of the oil at intervals of time. Further chilling was continued until the oil stop to flow. At this point, the temperature value is recorded. A NDJ-9S Digital Display Viscometer was employed. The spindle was put onto the viscometer and screwed to the chuck. The prepared sample was heated in a water bath to a temperature of $40^{\circ} \mathrm{C}$ in a $250 \mathrm{ml}$ beaker. The sample is transferred to the viscometer and placed on a fixture located at the base of the viscometer. The spindle of the viscometer is lowered into the fluid using an adjustable nub at the stand. The spindle is lowered until it is about $3 / 4$ below the fluid's surface. The viscometer is plugged to a power source, and is then turned ON. As the spindle is stirring the oil, it was observed the digital LED display meter. When the reading becomes steady, the reading was taken. At the end of each reading, the viscometer is turned OFF. Its spindle is adjusted upwards again, the oil removed and the spindle cleaned in readiness for another test. In all, about twenty runs were carried out for each sample and the results obtained. This process was repeated when the oil was heated to $100^{\circ} \mathrm{C}$.

The Corrosion test consists in measuring the corrosion grade of cutting fluid by its contact with cast iron. Some grams of cast iron chips, previously washed in acetone and dried, were placed on a piece of filter paper in a Petri dish. The chips were evenly spaced around the filter paper, preventing them from contacting one another and humidified with the sample of the test cutting fluid. The chips were left in the covered Petri dish for 2 hours. At the end of 2 hours, the iron chips were discarded and the filter papers were rinsed in acetone. The corrosion grade of the cutting fluid is measured by observation how many spots appeared in the filter paper surface. The objective of this analysis is to determinate the anticorrosive characteristics of the cutting fluids. Lastly, the $\mathrm{pH}$ of the cutting fluids was determined using a Surgifield digital pHmeter. Model SG061D. Always before the measurement, the pHmeter is calibrated with a standard solution.

After the cutting fluid development, these products were subjected to turning operation, which was carried out to test the performance of the spent engine oil based cutting fluids. Nine samples of cutting fluids were used in this study. First was a commercial cutting fluid and the other eight are cutting fluids developed from the spent engine oil. The spent engine oil based cutting fluids were in two groups:

Samples I-III: Mineral-based Cutting Fluids developed from spent engine oil without emulsifier.

Samples IV-VIII: Mineral-based Cutting Fluids developed from spent engine oil with emulsifier.

The turning experiments were carried out on a Conventional lathe machine (PAYSTAR 5000). A threejaw chuck was used for holding the workpiece. High Speed Steel (HSS) tool was used as a cutting tool. A mild steel bar of $40 \mathrm{~mm}$ diameter was used as a workpiece material. The Cutting speed, Feed rate, and Depth of cut were considered as machining/ process parameters. Measurements of Tool Tip Temperature, Material Removal Rate (MRR) and Tip Wear were obtained as output parameters to evaluate the machining efficiency of the samples of cutting fluids and of a dry cutting process. For the experiment, different cutting speeds, feed rates and depth of cut were employed.

In order to ascertain the ability of each sample cutting fluid to conduct heat away from the work zone, the workpiece was mounted on the three-jaw chuck of the lathe machine and a turning operation was carried out on the workpiece using the input parameters specified 
above for ten minutes while applying the cutting fluid(s) directly at the tool tip-work piece point of contact. A thermocouple made of Copper and Constantine wires (Type T) was used to measure the temperature right at the point where the tool tip made contact with the workpiece during chip removal. The procedure used is as described by Anyakoha [23]. The temperature reading was read from the thermocouple as electric voltage with the aid of a digital millivolt meter which was noted and recorded and the procedure was repeated for all samples at the specified process parameters. The obtained millivolts readings were converted to temperatures by the help of the conversion tables using interpolation where necessary. In this experiment, the work piece is weighed before turning and after turning for ten minutes is weighed again. The difference is recorded as the MRR measurement.

The Tip Wear was measured with the aid of vernier calipers. The Tip Wear of the insert is measured after every ten minutes of turning. The tool is replaced for another turning process.

\section{RESULTS AND DISCUSSION}

The summarized experimental results for flash point, pour point, $\mathrm{pH}$ value, viscosity and other properties of the samples of cutting fluids are shown in Table 2. For the flash points of the samples. It is seen that the Used Oil sample has a lower flash point of $184^{\circ} \mathrm{C}$ which is below the standard range of above $200^{\circ} \mathrm{C}$ [24]. The other 9 samples including a commercial cutting fluid have higher values of above $200^{\circ} \mathrm{C}$, with sample I giving the best pour point value of $206.11^{\circ} \mathrm{C}$ among the 8 processed samples. From the pour point results, it is observed that the pour point of the unblended spent engine oil is higher, which implies that it freezes faster than the blended samples of the spent engine oil and this makes it unsuitable for use.

The other 8 samples of cutting fluid obtained from spent engine oil have similar pour point average value, so can favourably compete with each other with sample
I having the best pour point value of $-13.53^{\circ} \mathrm{C}$. Again, the experimental result of the average $\mathrm{pH}$ values of the various samples of fluid show that the unblended sample of the spent engine oil is acidic (5.7); while those of the processed samples including commercial cutting fluid show that they are basic ranging between $8.94-9.1$. This, satisfying a property of cutting fluid.

In the $\mathrm{pH}$ results, sample VI gives a $\mathrm{pH}$ value of 9.08, which appears best among the processed samples. The viscosities obtained for the various samples of oil were obtained at $40^{\circ} \mathrm{C}$ and $100^{\circ} \mathrm{C}$. In the results, it is observed that the unblended spent engine oil has lower viscosity in relation to the processed samples and the commercial cutting fluid. Also among the processed samples, samples I-III have higher viscosity value compared to the remaining samples (IV-VIII) and the commercial cutting fluid, and this is attributed to the addition of emulsifying agent in the later samples. In the corrosion test results, the unprocessed lubricant presented a corrosive grade as against the other samples which did not show corrosiveness. The detailed report of the compared physical-chemical values of used engine oil and the other 9 samples of cutting fluids are analyzed and values are plotted in the bar graphs presented in Figure 1.

Based on the obtained results improvements are noticed in the different physical-chemical properties parameter of the treated spent engine oil. The improvement observed is due to the elimination of carbonaceous materials and volatile compounds. In general, an engine oil base stock with highly improved characteristics was realized through the regeneration process which effectively served as cutting fluid.

For the relative performance of the cutting fluids samples in terms of tool tip wear, material removal rate and tool tip temperature, the process parameters of cutting speed, feed rate and depth of cut were considered. Table 3, presents the result of the experiment carried out on these cutting fluid samples to observe their temperature response at prescribed input parameters.

Table 2: Summary of chemical-physical properties of the various fluids

\begin{tabular}{lccccccccccc}
\hline \multirow{1}{*}{ Properties } & \multicolumn{10}{c}{ Samples and their typical values } \\
\cline { 2 - 11 } & Used Oil & CUTSOL HD & I & II & III & IV & V & VI & VII & VIII \\
\hline Physical State & Liquid & Liquid & Liquid & Liquid & Liquid & Liquid & Liquid & Liquid & Liquid & Liquid \\
Colour & Black & Amber & - & - & - & - & - & - & - & - \\
Flash Point $\left({ }^{\circ} \mathrm{C}\right)$ & 184 & 214 & 206.11 & 205.74 & 205.77 & 205.77 & 205.86 & 206.08 & 205.92 & 205.93 \\
Pour Point $\left({ }^{\circ} \mathrm{C}\right)$ & -10 & - & -13.53 & -13.52 & -13.45 & -13.45 & -13.33 & -13.03 & -13.04 & -12.94 \\
Viscosity $(\mathrm{cst}) 40^{\circ} \mathrm{C}$ & 82.6 & 95 & 110.25 & 109.63 & 109.27 & 96.28 & 96.10 & 96.03 & 96.06 & 96.12 \\
Viscosity (cst) $100^{\circ} \mathrm{C}$ & 9.8 & 8.9 & 13.45 & 12.4 & 12.05 & 8.76 & 8.65 & 7.51 & 7.57 & 7.53 \\
pH Value & 5.7 & 9.1 & 9.02 & 9.0 & 8.94 & 8.94 & 8.99 & 9.08 & 9.06 & 9.03 \\
Corrosion Grade & 1 & 0 & 0 & 0 & 0 & 0 & 0 & 0 & 0 & 0 \\
\hline
\end{tabular}


From the results obtained, dry cutting, has the highest mean temperature value of $70^{\circ} \mathrm{C}$. For the other 9 samples with their mean temperatures ranging between $32.5-37.4^{\circ} \mathrm{C}$, Sample VII presented the least mean temperature of $32.5^{\circ} \mathrm{C}$.Comparing the results of the various fluid samples on cutting tool tip wear in Table 4; it is observed that on dry machining, the tool wear is maximum. Observing the mean tool wear values of the other 9 fluid samples, they fall within range of $0.402 \mathrm{~mm}$ to $0.482 \mathrm{~mm}$. From these range of values, Sample III presents the minimum mean value of tool tip wear.

The experimental result of Material Removal Rate is shown in Table 5. From this result; at dry machining, the rate of material removal is low with a mean value of $3.08 \mathrm{~g} / \mathrm{min}$ in comparison with when cutting fluid is applied with mean value range of $5.56-5.68 \mathrm{~g} / \mathrm{min}$. For the 9 cutting fluid samples used, Sample VII gave the best MRR mean value of $5.68 \mathrm{~g} / \mathrm{min}$.

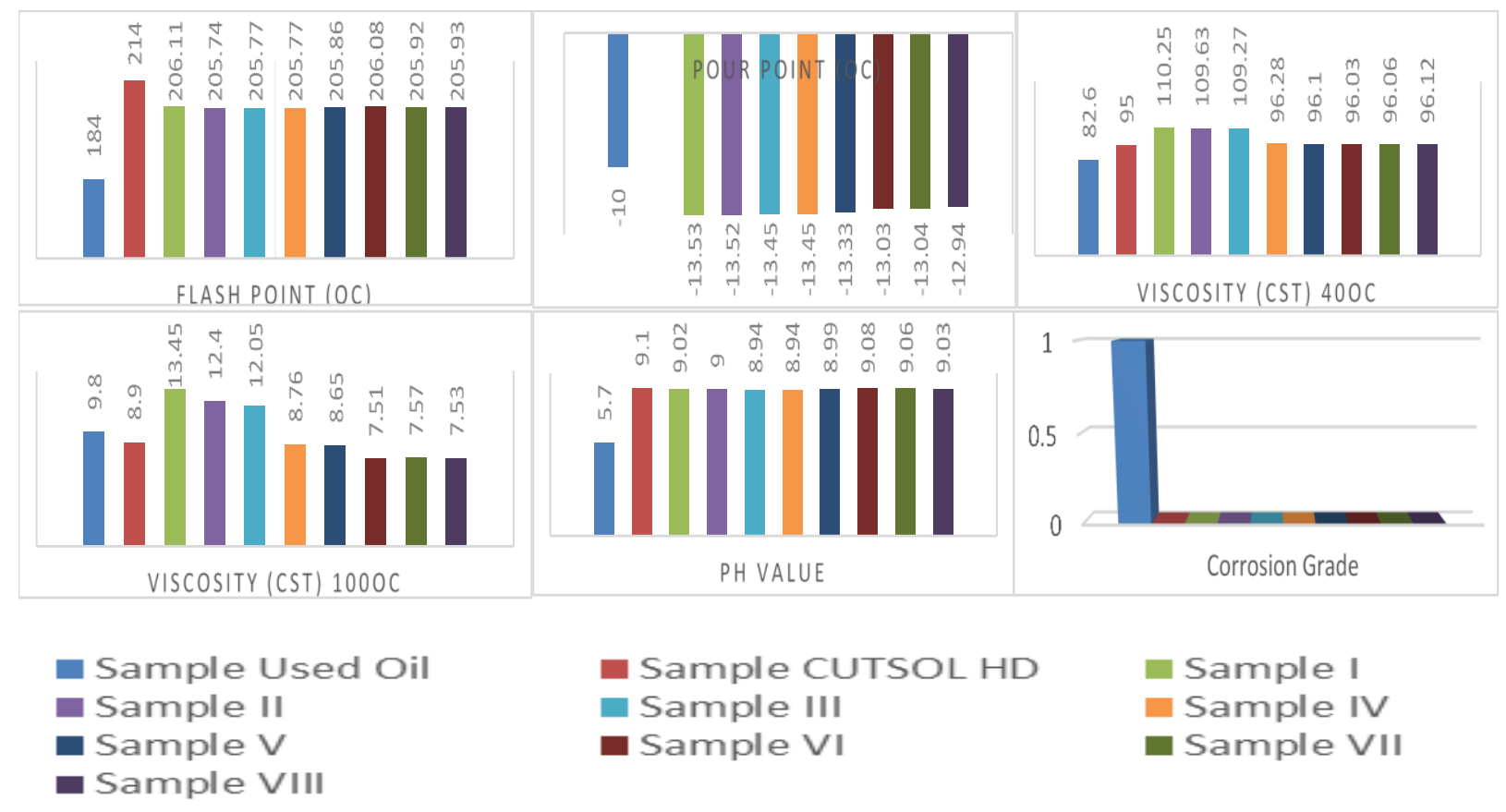

Figure 1: Comparative analysis graphs of physical-chemical properties values of the various fluids

Table 3: Temperature Test at varied Process Parameters

\begin{tabular}{|c|c|c|c|c|c|c|c|c|c|c|c|c|}
\hline \multirow{3}{*}{$\begin{array}{l}\text { Speed } \\
(\mathrm{m} / \mathrm{min})\end{array}$} & \multirow{3}{*}{$\begin{array}{l}\text { Feed Rate } \\
(\mathrm{mm} / \mathrm{rev})\end{array}$} & \multirow{3}{*}{$\begin{array}{l}\text { Depth of } \\
\text { Cut(mm) }\end{array}$} & \multicolumn{10}{|c|}{ Temperature $\left({ }^{\circ} \mathrm{C}\right)$} \\
\hline & & & \multicolumn{10}{|c|}{ Samples } \\
\hline & & & Dry & $\begin{array}{c}\text { CUTSOL } \\
\text { HD }\end{array}$ & I & II & III & IV & $\mathrm{V}$ & VI & VII & VIII \\
\hline 100 & 0.2 & 0.15 & 48 & 19 & 19 & 20 & 20 & 20 & 19 & 20 & 20 & 19 \\
\hline 110 & 0.4 & 0.2 & 52 & 22 & 22 & 23 & 24 & 22 & 24 & 23 & 22 & 23 \\
\hline 120 & 0.6 & 0.25 & 57 & 26 & 26 & 27 & 29 & 27 & 25 & 26 & 25 & 25 \\
\hline 130 & 0.8 & 0.3 & 64 & 29 & 30 & 29 & 32 & 29 & 28 & 29 & 28 & 29 \\
\hline 140 & 1 & 0.35 & 69 & 32 & 32 & 33 & 35 & 33 & 32 & 31 & 31 & 31 \\
\hline 150 & 1.2 & 0.4 & 72 & 35 & 37 & 36 & 39 & 35 & 34 & 34 & 34 & 35 \\
\hline 160 & 1.4 & 0.45 & 76 & 38 & 42 & 40 & 43 & 38 & 37 & 38 & 37 & 39 \\
\hline 170 & 1.6 & 0.5 & 81 & 41 & 47 & 44 & 48 & 41 & 39 & 40 & 40 & 41 \\
\hline 180 & 1.6 & 0.55 & 87 & 44 & 52 & 49 & 51 & 44 & 44 & 44 & 43 & 45 \\
\hline 200 & 1.8 & 0.6 & 94 & 47 & 55 & 54 & 53 & 46 & 46 & 47 & 45 & 47 \\
\hline
\end{tabular}


Table 4: Tip Wear at varied Process Parameters

\begin{tabular}{|c|c|c|c|c|c|c|c|c|c|c|c|c|}
\hline \multirow{3}{*}{$\begin{array}{c}\text { Speed } \\
(\mathrm{m} / \mathrm{min})\end{array}$} & \multirow{3}{*}{$\begin{array}{l}\text { Feed Rate } \\
(\mathrm{mm} / \mathrm{rev})\end{array}$} & \multirow{3}{*}{$\begin{array}{l}\text { Depth of } \\
\text { Cut }(\mathrm{mm})\end{array}$} & \multicolumn{10}{|c|}{ Tip Wear (mm) } \\
\hline & & & \multicolumn{10}{|c|}{ Samples } \\
\hline & & & Dry & $\begin{array}{c}\text { CUTSOL } \\
\text { HD }\end{array}$ & I & II & III & IV & V & VI & VII & VIII \\
\hline 100 & 0.2 & 0.15 & 0.5 & 0.3 & 0.28 & 0.28 & 0.26 & 0.32 & 0.3 & 0.3 & 0.34 & 0.32 \\
\hline 110 & 0.4 & 0.2 & 0.5 & 0.36 & 0.32 & 0.3 & 0.28 & 0.34 & 0.3 & 0.32 & 0.36 & 0.36 \\
\hline 120 & 0.6 & 0.25 & 0.6 & 0.4 & 0.36 & 0.34 & 0.32 & 0.38 & 0.34 & 0.36 & 0.4 & 0.38 \\
\hline 130 & 0.8 & 0.3 & 0.64 & 0.42 & 0.4 & 0.38 & 0.36 & 0.42 & 0.38 & 0.4 & 0.44 & 0.42 \\
\hline 140 & 1.0 & 0.35 & 0.68 & 0.46 & 0.4 & 0.4 & 0.38 & 0.48 & 0.4 & 0.4 & 0.48 & 0.44 \\
\hline 150 & 1.2 & 0.4 & 0.7 & 0.5 & 0.44 & 0.44 & 0.42 & 0.52 & 0.44 & 0.46 & 0.5 & 0.5 \\
\hline 160 & 1.4 & 0.45 & 0.7 & 0.54 & 0.46 & 0.46 & 0.46 & 0.54 & 0.5 & 0.5 & 0.52 & 0.54 \\
\hline 170 & 1.6 & 0.5 & 0.76 & 0.56 & 0.5 & 0.48 & 0.5 & 0.58 & 0.54 & 0.56 & 0.56 & 0.56 \\
\hline 180 & 1.6 & 0.55 & 0.8 & 0.58 & 0.52 & 0.5 & 0.5 & 0.58 & 0.58 & 0.58 & 0.6 & 0.58 \\
\hline 200 & 1.8 & 0.6 & 0.86 & 0.6 & 0.56 & 0.54 & 0.54 & 0.62 & 0.6 & 0.64 & 0.62 & 0.62 \\
\hline
\end{tabular}

Table 5: Material Removal Rate at varied Process Parameters

\begin{tabular}{|c|c|c|c|c|c|c|c|c|c|c|c|c|}
\hline \multirow{3}{*}{$\begin{array}{l}\text { Speed } \\
(\mathrm{m} / \mathrm{min})\end{array}$} & \multirow{3}{*}{$\begin{array}{l}\text { Feed Rate } \\
(\mathrm{mm} / \mathrm{rev})\end{array}$} & \multirow{3}{*}{$\begin{array}{l}\text { Depth of } \\
\text { Cut(mm) }\end{array}$} & \multicolumn{10}{|c|}{ Material Removal Rate (g/min) } \\
\hline & & & \multicolumn{10}{|c|}{ Samples } \\
\hline & & & Dry & $\begin{array}{c}\text { CUTSOL } \\
\text { HD }\end{array}$ & I & II & III & IV & $\mathrm{V}$ & VI & VII & VIII \\
\hline 100 & 0.2 & 0.15 & 1.3 & 3.4 & 3.5 & 3.3 & 3.4 & 3.5 & 3.4 & 3.4 & 3.3 & 3.2 \\
\hline 110 & 0.4 & 0.2 & 1.7 & 3.8 & 3.8 & 3.9 & 4 & 3.9 & 3.9 & 3.9 & 3.8 & 3.9 \\
\hline 120 & 0.6 & 0.25 & 2 & 4.3 & 4.4 & 4.5 & 4.3 & 4.4 & 4.3 & 4.4 & 4.5 & 4.4 \\
\hline 130 & 0.8 & 0.3 & 2.5 & 4.9 & 4.8 & 5 & 4.8 & 4.9 & 4.8 & 4.9 & 5 & 4.8 \\
\hline 140 & 1 & 0.35 & 2.9 & 5.4 & 5.5 & 5.3 & 5.4 & 5.6 & 5.4 & 5.5 & 5.6 & 5.5 \\
\hline 150 & 1.2 & 0.4 & 3.2 & 6 & 5.9 & 5.9 & 5.8 & 6 & 6 & 5.9 & 6 & 5.8 \\
\hline 160 & 1.4 & 0.45 & 3.7 & 6.3 & 6.5 & 6.3 & 6.4 & 6.4 & 6.5 & 6.3 & 6.4 & 6.5 \\
\hline 170 & 1.6 & 0.5 & 4.2 & 6.8 & 6.9 & 6.8 & 6.8 & 6.7 & 6.8 & 6.7 & 6.9 & 6.9 \\
\hline 180 & 1.6 & 0.55 & 4.5 & 7.2 & 7.4 & 7.4 & 7.5 & 7.3 & 7.4 & 7.4 & 7.5 & 7.4 \\
\hline 200 & 1.8 & 0.6 & 4.8 & 7.5 & 7.7 & 7.8 & 7.8 & 7.7 & 7.9 & 7.9 & 7.8 & 7.9 \\
\hline
\end{tabular}

\section{CONCLUSION}

With the increase in concerns about the disposal of spent lubricants, the waste-to-wealth programme offers the best alternative for utilizing these substances. From the work undertaken, samples of cutting fluid were formulated from spent engine oil. From the performance analysis, the optimal sample have values such as flash point, $205.92^{\circ} \mathrm{C}$; pour point, $13.04{ }^{\circ} \mathrm{C}$. Viscosity, at $40^{\circ} \mathrm{C}$ gave an average value of $96.06 \mathrm{cst}$. At $100^{\circ} \mathrm{C}$, the average values is $7.57 \mathrm{cst}$. The sample have average $\mathrm{pH}$ value of 9.03. In corrosion grading, it rated non-corrosive. Further evaluation of the cutting fluid samples with respect to tool tip wear, material removal rate and tool tip temperature measurements was done. Generally, all the blended samples of spent engine oil based cutting fluids presented good cutting fluid characteristics and dependable substitute for the conventional cutting fluids in use, which are not affordable for most small scale machine shops that resort to dry machining as their only known alternative. Therefore with these findings, the level of indiscriminate disposal of spent engine oil should be discouraged to reduce pollution, since it can be put into good alternative uses.

\section{REFERENCE}

[1] Udonne J. D. "A comparative study of recycling of used lubrication Oils using distillation, acid and activated charcoal with clay methods"; Journal of Petroleum and Gas Engineering Vol. 2 (2), pp. 1219, 2011.

[2] Durrani, H.A., Panhwar, M. I., Kazi, R. A., "ReRefining of waste lubricating oil by solvent extraction", Mehran University Research Journal of Eng. \& Tech., [ISSN 0254-7821], 30 (2) pp 237 246, 2011.

[3] Kamal, A., Khan, F., "Effect of extraction and adsorption on re-refining of used lubricating oil", Oil \& Gas Science and Technology, 64 (2), pp 191197, 2009. 
[4] Ogbeide S. O. "An Investigation To The Recycling of Spent Engine Oil"; Journal of Engineering Science and Technology Review 3 (1), pp 32-35, 2010.

[5] Ihsan Hamawand, Talal Yusaf, and Sardasht Rafat "Recycling of Waste Engine Oils Using a New Washing Agent"; Energies, 6, pp 1023-1049, 2013.

[6] Kajdas, C. "Major pathways for used oil disposal and recycling", Part 1. Tribotest Journal. 2000, 7, pp 61-74, 2000.

[7] Boughton, B. and Horvath, A. "Environmental assessment of waste oil management methods" Environ. Sci. Technol., 38, pp 353-358, 2004.

[8] Eman A. Emam and Abeer M. Shoaib "Re-refining of Used Lube Oil, II- by Solvent/Clay and Acid/Clay-Percolation Processes"; ARPN Journal of Science and Technology; vol. 2, no. 11, pp 10341041, 2012.

[9] Ávila, R. F. and Abrão, A. M. "The effect of cutting fluids on the machining of hardened AISI 4340 steel," Journal of Materials Processing Technology, No. 119, pp 21-26, 2001.

[10] Kuram E., Ozcelik B., Demirbas E. and Sik E. "Effects of the Cutting Fluid Types and Cutting Parameters on Surface Roughness and Thrust Force" Proceedings of the World Congress on Engineering 2010, June 30 - July 2, 2010, London, U.K., Vol II, pp 4-8, 2010.

[11] Nagpal, G. R. "A Textbook on Machine Tool Engineering". Khanna Publishers, Brahmpuri, Delhi 10053, India. 2004, pp. 243-266.

[12] Rushikesh Waydande and Dayanand Ghatge "Performance Evaluation of Different Types of Cutting fluids in the Machining of hardened steel a Review"; International Journal of Mechanical and Production Engineering, Vol. 4, Issue 3, pp 3439, 2016.

[13] Cecil M. D., Rao K. V. C., Walter W. O., and John W. S. "Effect of Cutting Fluid Properties and Applications Variables on Heat Transfer in Turning and Boring Operations", Japan/ USA Symposium on Flexible Automation, Vol. 2, pp 1-6. 1996.
[14] Weinert, K., Inasaki, I., Sutherland, J. W., Wakabayashi, T., "Dry Machining and Minimum Quantity Lubrication”, CIRP Annals, Vol. 53, Iss. 2, pp. 511-537, 2004.

[15] Brinkmeier E., Garbrecht M., Heinzel C., Koch Th., and Eckebrecht J. "Current Approaches in Design and Supply of Metal Cutting Fluids" Foundation Institute of Material Science, Bremen, Germany, pp 36-38. 2010.

[16] Neil Canter "The possibilities and limitations of dry machining" Tribology \& Lubrication Technology Series, pp 40-44, 2009.

[17] Durrani H. A, Panhwar M. I, Kazi R. A, "Determining an efficient solvent extraction parameters for re-refining of waste lubricating oils", Mehran University Research Journal of Eng. \& Tech., 31 (2), pp 265-270, 2012

[18] Olufemi A. O. and Oladeji A. O. "Use of Spent Engine Oil" Department of Mechanical Engineering, Federal University of Technology Minna, Niger State, Nigeria, AU J.T., (Jul. 2008), 12(1), pp 67-71, 2008.

[19] Oboh, A. O.; and Aworh, 0. C. "Bleaching performance of selected acid-activated Nigerian clays on some common pre-bleach crude palm oil feedstocks", Nigerian Food Journal, vol. 9, pp 2025: 1991

[20] Okwara C. A. and Osoka E. C. "Caustic Activation of clays for palm oil bleaching"; Journal of Engineering and Applied Sciences 1 (4), pp. 526529, 2006.

[21] Ibhadode A. O. "Introduction to Manufacturing Technology", Ambik publishers, Benin- Nigeria, 2001.

[22] Chapman W. A. J. "Workshop Technology", Edward Arnold Publishers Limited, U.K, pp. 167191. 1972.

[23] Anyakoha, M. W. "New School Physics for Senior Secondary Schools"; Africana First Publishers Onitsha, pg 74, 2000.

[24] Sharma P. C. "A Textbook of Production Technology", S. Chand and Co. New Delhi, , pp. 412-416 2005. 